\title{
EUROPEAN INTEGRATION PERSPECTIVES: FROM COHESION TO DIVERGENCE?*
}

\author{
Vedran RECHER - Nataša KURNOGA \\ (Received: 7 May 2015; 11 November 2015; \\ accepted: 15 December 2015)
}

\begin{abstract}
This paper examines the impact of EU enlargement and the global economic crisis on the relative development of the EU countries. This effect is assessed by applying multivariate analysis to the whole set of 28 European countries at three representative points in time. The cluster analysis for the years 2002, 2007, and 2012 grouped the countries according to the range of economic development indicators showing within-EU cohesion before the EU enlargement, after the enlargement wave, and after the crisis. The findings show that a decrease in the development differences after the enlargement was replaced with an increase in these differences after the crisis, thus contributing to the existing debate about the success of cohesion and future of European integration. These results are somewhat worrying for the new member states of the EU as well as for EU membership candidates and their prospective development within the integration.
\end{abstract}

Keywords: development, convergence, cohesion, European integration, multivariate analysis

JEL classification indices: D63, E60, F15, O10

* We gratefully acknowledge the support and helpful inputs from Jelena Budak, Marina Tkalec, and Ivan Žilić in developing the ideas presented here. We also thank the two anonymous reviewers for their valuable remarks and contribution to the overall quality of the paper.

Vedran Recher, corresponding author. Research Assistant at the Institute of Economics, Zagreb, Croatia. E-mail: vrecher@eizg.hr,

Nataša Kurnoga, Professor at the Faculty of Economics and Business, University of Zagreb, Croatia. E-mail: nkurnoga@eizg.hr 


\section{INTRODUCTION}

The process of European integration started more than half a century ago. In this period, the economic environment and geographic outlook of integration have changed significantly. In accordance with these changes, the policies needed to achieve optimum economic impacts were also modified. As European integration was widening, the debate about the differences in the level of development of member states has been growing. European convergence policy began in 1986 by including the objective of "economic and social cohesion" into the Single European Act. It was believed that certain areas within the Community might not be able to develop at the same pace as some other areas within the Single Market. The European Union defines "economic and social cohesion" as an expression of solidarity between the Member States (MS) and regions of the European Union, which means balanced and sustainable development, reducing structural disparities between regions and countries, and promoting equal opportunities for all individuals (Welcome Europe 2015). The discussion about the economic success of these policies focused on economic cohesion is still very vivid (Kamps et al. 2009; Hagen - Mohl 2009; Dăianu 2012), especially after the Eastern enlargement in 2004 (Dobre 2010; Panagiotou 2013). Furthermore, because of the fact that the conclusions about these policies from the literature are still ambiguous (Sala-i-Martin 1996; Boldrin - Canova 2001; Martin 2005; Bouvet 2010), the perspective for the further development of new member states (NMS) is vague. Winiecki (2012) goes even further and labels the debate about euro zone's problems as "an irritating superficiality". This study attempts to shed more light on this issue, with regard to the greatest enlargement in the history of EU in 2004 and the great recession of 2008. Here, superficiality of the analysis is avoided by observing the differences and similarities in the level of development among MS in chosen reference years and by taking into account a set of variables that indirectly or directly define economic development in its broader sense. Did the cohesion policy succeed in its stated purpose despite of the crisis?

As stated in the definition of social and economic cohesion, well-being and the structure of national economies should become more akin inside the integration and therefore more resistant to exogenous shocks such as the global economic crisis, which suggests that the standard economic growth and development, and living standard indicators should be included in the analysis. Furthermore, rationale suggests that integration, along with cohesion policy, would increase the economic prosperity of nations by reducing structural problems such as unemployment, in particular long-term unemployment, and improve the situation of old workers, youth, women, and other vulnerable population groups whose situation is expected to further deteriorate in times of crisis. If older people have 
less formal qualifications and are more vulnerable to technological change in favour of skills (Disney - Hawkes 2003), even though older people are generally better protected (Leschke - Watt 2010), it is expected that the employment of older workers would decrease more in relatively less developed countries because of the structural defects inherent to these economies compared to more developed EU members. Vice versa intuition suggests young people are more educated and technologically literate, and could therefore be the driving force of future development, hence the demographic structure of the society should be considered as well.

The paper is structured as follows. The next section provides a brief overview of the selected EU enlargement literature that is closely related to the subject of this study. Section 3 describes the developed model, the data sources, and the methodology applied to yield the results of multivariate analysis presented in Section 4. Findings are discussed in terms of ongoing scholarly debate about the success of European integration, and conclusions are offered in the last section.

\section{EASTERN ENLARGEMENT DEBATE}

The success of the Eastern enlargement has been studied extensively (Agnew 2001; Reinert - Kattel 2007; Breuss 2009; Hlavac 2010). We are concerned only with the economic effects of the integration and we differentiate these studies from other research dealing mostly with institutional convergence (see, e.g., López-Tamayo et al. 2014).

Ottaviano et al. (2007) modelled the effect of the impact of accession of countries to the European Monetary Union and the 2004 enlargement on competitiveness. They conclude that the impact is two-fold: improved accessibility of NMS, but significantly increased relative importance of non-productive enterprises from Eastern Europe. Breuss (2009) argues that the expansion in 2004 and 2007 was a result of political motives, while previous expansions were means to achieve economic objectives - the expansion of the Single Market and monetary union with a single currency. Nevertheless, Breuss (2009) believes that the expectations of NMS of the European integration had been completely fulfilled: all countries have grown faster than before integration. The labour markets improved their performances in most countries, fiscal consolidation was successful everywhere except Hungary, and the trade between new and old member states expanded. Hlavac (2010) believes that the enlargement in 2004 and 2007 had a positive impact on NMS since they had to undertake the political, economic, and social reforms, which consolidated their democracies and enhanced their market economies. Vachudova (2013) gives an even more decisive judgment on the success of 
the enlargement, emphasising the benefits for both old and new MS and argues that the enlargement was the most successful exampley of democracy promoting in history. However, there is no consensus regarding the positive or negative impact of enlargement. Reinert - Kattel (2007) contend that the expansion of the EU brought a qualitative shift from symmetrical to asymmetrical integration; a process that culminated with the 2004 enlargement. Furthermore, the authors argue that this shift represents a threat to Europe's prosperity for both the core and periphery. Meardi (2012) also claims that workers in new member states no longer have access to the "social Europe", but are the victims of stagnation and even deterioration of social and working conditions, while their capacity for collective action is politically marginalised and de facto non-existent.

In this paper, we build on the classification of EU countries into clusters according to structural economic indicators using factor and cluster analysis (Kurnoga- Zivadinovic et al. 2009). Their preliminary classification was based on only three structural economic indicators. This paper takes multivariate analysis further by using different points in time and a larger set of variables to monitor the changes that have occurred during the analysed period. This approach enables us to inspect the dynamics of the changes in similarities and discrepancies between European MS during the analysed period. This form of analysis is lacking in the existing debate about the achievements of the European integration and may be seen as a contribution to the extant literature.

\section{METHODOLOGY AND MODEL}

The analysis is conducted for three years: 2002, 2007, and 2012, each one denoting one specific point in time for European integration. Year 2002 is chosen as a reference point before the EU largest enlargement that occurred in 2004. Year 2007 is chosen to observe the potential changes in the clustering due to the enlargement, but before the crisis struck. The last year for which all data were available is 2012, and it is interesting to examine the changes in clustering as a result of the crisis. Analysis is conducted for $28 \mathrm{EU}$ member states, as of 2013. It is worth noting that the analysis is conducted for all countries in the EU-28 sample for every year observed. Thus, for example, Croatia as the most recent EU member state as of July 1, 2013, is included in the analysis for the whole period. It enables us to investigate to which cluster a new member state would belong, regardless of its EU membership at that time. This is useful for examining the differences in clustering before and after the EU accession, i.e. it determines the impact of EU accession on cluster membership. 
Data are obtained from the World Bank (2013) and the European Commission (2014). The data set totalling 19 economic variables was tested for multicollinearity through Variance Inflation Factor (VIF), since multicollinearity could impact the results of cluster analysis significantly. After examining multicollinearity, 9 variables were chosen: Itun (long-term unemployment in \% of active population), eldem (employment rate of older workers), lifeex (life expectancy at birth), gdp (real GDP per capita), urbpop (urban population in \% of total), imex (exportimport coverage ratio), dep (age dependency ratio, old $\%$ of working-age population), prem (employment in agriculture in \% of total employment), and femact (female activity rate for females aged 15-64). These variables are included in the model because they stand as good proxies for economic prosperity and countries are clustered according to these indicators of economic development.

The long-term unemployment indicator is used because by entering the single European market, the mobility of the workforce increases and the labour market is expected to resolve imbalances more easily, and therefore long-term unemployment is expected to fall (Kahanec et al. 2010). Furthermore, long-term unemployment is more appropriate than the basic rate of unemployment since the variation in short-term unemployment is substantially smaller than in long-term unemployment (Nickell 1997), i.e. it is easier to notice the differences between countries through time for long-term unemployment. The employment rate of older workers is chosen because it is a good proxy variable for the impact of the crisis. It is expected that the less affected countries would have a near-constant rate of employment of older workers, while this rate would decline in more affected countries (Disney - Hawkes 2003; Leschke - Watt 2010). Life expectancy at birth is a proxy variable for general well-being (e.g. Balezentis et al. 2011), as is GDP per capita and the proportion of the urban population (O'Sullivan 2011). The export-import coverage ratio approximates country competitiveness. The age dependency ratio serves as an indicator of development potential: the lower the age dependency, the higher the development potential and vice versa. Employment in agriculture is also good approximation of the relative development since developed countries have smaller agricultural sector relative to their GDP. The female activity rate denotes the equality of the sexes, which is also connected to development because developed countries generally have greater gender equality than developing countries. Based on this set of variables, we proceed with the multivariate analysis of EU member states. 


\section{RESULTS OF MULTIVARIATE ANALYSIS}

The set of chosen variables in the model has been used to conduct a hierarchical cluster analysis, followed by the K-means cluster analysis and discriminant analysis. Ward's method with squared Euclidian distances is used for the hierarchical cluster analysis. Hierarchical analysis offers a possible number of clusters. Based on the results of hierarchical analysis, three clusters are chosen for conducting the K-means cluster analysis. A summary of the K-means cluster analysis for all years can be found in the Appendix for the convenience of the reader. Discriminant analysis is then conducted to check the results of the cluster analysis. The three-step multivariate analysis is performed for three periods: before the great enlargement (2002), after the enlargement and before the crisis (2007), and after the crisis (2012).

\subsection{EU integration clusters before the enlargement}

In 2002, the EU consisted of 15 states. Therefore it is interesting to observe the grouping of the countries before the 12 NMS entered the integration. First, a cluster analysis on standardised values is conducted.

Based on the dendrogram of Ward's method of hierarchical cluster analysis with squared Euclidian distances, the solution with three clusters is chosen. The first cluster consists of 13 countries (Belgium, Spain, Italy, Germany, France, Austria, Luxembourg, Czech Republic, Cyprus, Ireland, Hungary, Slovenia, and Malta), the second of 5 countries (Denmark, Finland, the Netherlands, UK, and Sweden), and a third of 10 countries (Bulgaria, Croatia, Poland, Slovakia, Estonia, Lithuania, Latvia, Romania, Greece, and Portugal). Obviously, clusters are not clearly separated with regard to the EU membership. The third cluster is made up of NMS (and Croatia, which was not a member during the whole analysed period), except for the Czech Republic, Cyprus, Slovenia, Malta, and Hungary, and with the addition of Greece and Portugal from among the old MS. Generally, countries are grouped in accordance with their historical, political, social, geographic, and economic conditions. However, it is interesting that Slovenia is grouped in a relatively more developed cluster compared to Croatia, even though they have very similar historical and geographical properties. This might be due to the fact that in 2002, Croatia was still in a post-war recovery period.

To confirm the results of the hierarchical cluster analysis, the K-means method of unhierarchical cluster analysis for three clusters is conducted. The second cluster consists of third-cluster countries from Ward's method, with the addition of Hungary and Slovenia. Therefore, it could be said that the K-means solution is 
somewhat more intuitive because the second cluster now consists of all new MS, with the addition of Greece and Portugal. This cluster is denoted as the underdeveloped cluster. The Czech Republic, Cyprus, Malta, and Ireland moved from the first to the third cluster, which is depicted as a semi-developed cluster, while Denmark, the Netherlands, Sweden, Finland, and the UK all moved to the first cluster. Now, there are no NMS in the first cluster, it consists of only the most developed countries. The graph representing the means of the three clusters is shown in Figure 1.

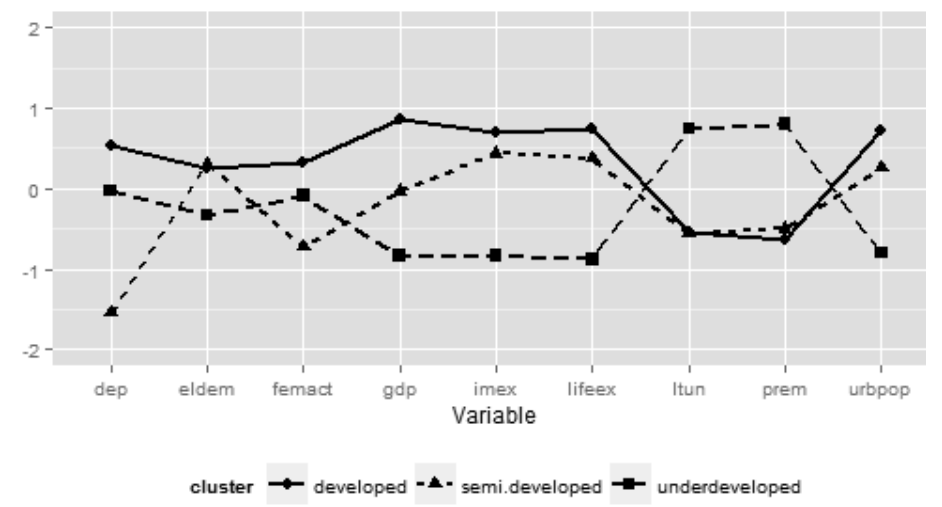

Figure $1 .{ }^{1}$ Means of the three clusters in 2002 (K-means)

It is apparent from Figure 1 that the first, most developed cluster has low longterm unemployment and primary sector employment, and high life expectancy at birth, real GDP p.c., share of urban population, export-import coverage ratio, and female activity rate. Furthermore, a separated cluster with the Czech Republic, Malta, Ireland, and Cyprus is obviously a semi-developed cluster - a mixture of new and old MS. This cluster differs predominantly in demographic variables (dep and femact) and in female activity it fares worse than the other two clusters. The only variable in which there is relative similarity between the three clusters is elderly employment.

Finally, discriminant analysis is conducted for the K-means solution. Variables eldem, lifeex, urbpop, dep, and femact contribute the most to cluster separation (p-value $<0.1$ ). This result fits in with the results of the cluster analysis because Figure 1 suggests that with separation of the Czech Republic, Malta, Cyprus, and Ireland, significant differences in demographic variables occur. Additionally, the 
classification matrix obtained by discriminant analysis showed that all countries are correctly divided into clusters.

For 2002, the cluster analysis results show significant differences. The solution with three clusters clearly separates old MS from those which joined the EU in 2004 and in 2007, which is in line with the asymmetrical integration hypothesis of Reinert - Kattel (2007). Obviously, before the eastern enlargement, current EU member states differed significantly in their levels of development. In order to observe the potential changes in country grouping due to the enlargement, the next analysed year is 2007 .

\subsection{EU integration clusters after enlargement and before the crisis}

Taking into account the goals of cohesion policy, one should expect a reduction in the gap between regions and countries inside the EU. If there is indeed a convergence among new and old MS, then (i) more countries would join the relatively more developed cluster, or (ii) the gap between the clusters containing the same countries would decrease.

Again, cluster analysis on standardised values is conducted with Ward's method with squared Euclidian distances. The composition of clusters is identical to the hierarchical cluster analysis in 2002. K-means method of unhierarchical cluster analysis is conducted for three clusters. K-means results in 2007 show some differences in comparison to 2002. The first cluster still consists of the most developed countries, with the addition of the Czech Republic, Ireland, Cyprus, and Malta (which were separated into their own cluster in 2002) and this cluster is now the developed one. The second cluster contains new MS, Greece, Portugal, and Croatia, and is denoted as underdeveloped cluster 1. Unlike in 2002, the third cluster now consists of Bulgaria and the Baltic countries (Estonia, Lithuania, and Latvia) and it is marked as underdeveloped cluster 2. It seems that this separated cluster with only four countries is now somewhat underdeveloped in comparison with the separated cluster in 2002, hence the change in the name of the separated cluster. Because it is hard to unambiguously determine which of the two latter clusters is more/less developed, they are both labelled as underdeveloped clusters. According to the distances from the cluster centre, the separated cluster (underdeveloped cluster 2) is the most homogeneous (distances from 0.35 to 0.53 ). Furthermore, Ireland, Cyprus, and Malta have relatively high distances from the cluster centre $(0.89,0.91$ and 1.37 , respectively), which does not come as a surprise in the light of the 2002 cluster analysis results when they had formed a separate cluster. The reason behind this probably lies with different variables being the most significant discriminators between country groups. Therefore, one 
should not read too much into the fact that they are now labelled as developed in the European context, especially for Cyprus and Malta. However, the Czech Republic is rather close to the cluster centre of the developed cluster $(0.64)$, which illustrates the fact that the Czech Republic might have used the advantages of EU membership and the Single Market to close the gap from the core. It should in all fairness be added that the Czech Republic put in significant efforts in the period before the accession to substantially improve the business climate by liberalising the services sector and opening the economy (Arnold et al. 2011), and therefore its success should not be attributed solely to EU membership. The same applies for other countries as well. Their policies and reforms adopted in the course of the accession had synergic effects on their respective development, and not the EU membership per se. Therefore, we observe how the countries capitalised the opportunities provided by EU membership and enlargement, and not how EU membership in itself changed their level of development in comparison with other MS. For an additional analysis of the development disparities, it is instructive to look at Figure 2 with the means of the three clusters in 2007.

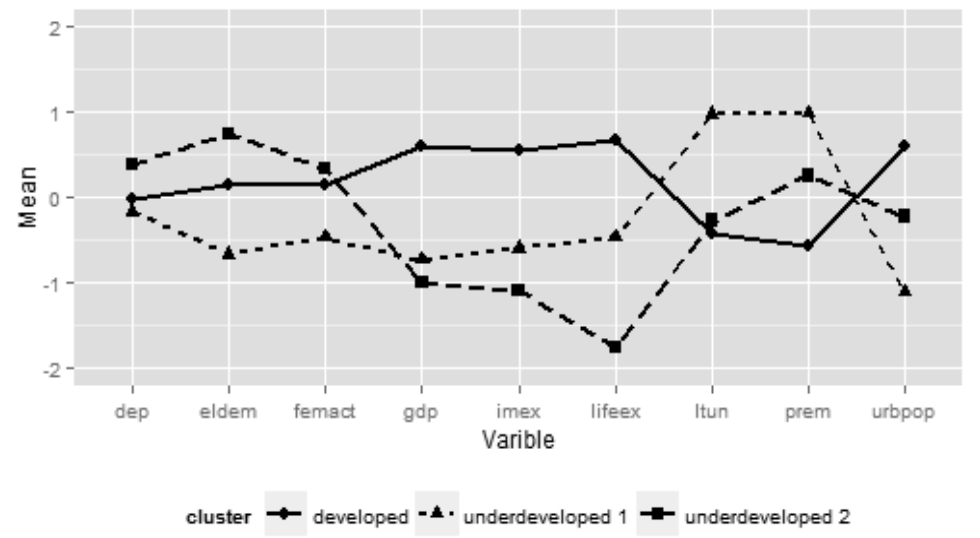

Figure 2. Means of the three clusters in 2007 (K-means)

The differences in comparison to 2002 are not immediately clear. However, if the differences between means are observed more carefully, moderate convergence in most variables becomes visible. Whereas it was in the period of only five years, this result is in line with cohesion policy goals. Of course, it is important to emphasise that regional convergence (which is also one of cohesion policy goals) is not covered here, but only convergence between countries. This result can be attributed to several facts: (i) economic growth and general optimism after the creation of the EMU in 2000; (ii) significantly higher marginal product of 
capital in the periphery in comparison to Western Europe (Lipshitz et al. 2006), which attracts foreign investments; (iii) credit boom and accumulating current account imbalances, which fuelled consumption (Schmitz - von Hagen 2011; Lane - McQuade 2014), while at the same time raising the vulnerability of these countries to the external shocks, which will be addressed in the next section; and (iv) shifting of fiscal policy from countercyclical more towards procyclical (Bénétrix - Lane 2013), which had an impact on enhancing the magnitude of growth rates, but likewise of potential downfall. Therefore, the results confirm the highlighted fact from Lipshitz et al. (2006) that Europe had slow real convergence in the period 2002-2007. It is important to note that point (ii) refers to the average impact of FDI from more to less developed EU member states. Weinhold - Nair-Reichert (2001) emphasise that there is considerable heterogeneity across countries regarding the impact of FDI on economic growth, while Alfaro et al. (2007) highlight the importance of institutional quality and policy as determinants of capital inflows. Therefore, large FDI inflows to CEE countries in this period (Lane-Milesi-Ferretti 2007) should not be observed as the main antecedent of observed convergence, but rather as an indication of institutional advancements and policies implemented which resulted in some countries being better off, while the average level of development in NMS also increased. Furthermore, Bogumil (2014) provides evidence for the positive impact of FDI on growth, but argues that while FDI into construction and real estate had a positive impact on growth, it fuelled asset price bubbles and was not sustainable. On the other hand, in some countries such as Poland, FDI were directed towards the tradable sector and supported strong export growth without fuelling credit and substantial asset price booms, which proved to be a better long-term strategy.

It is clear from Figure 2 that the developed cluster is again distinguished as being the most advanced with the lowest long-term unemployment and employment in agriculture, and the highest GDP per capita, life expectancy at birth, percentage of the urban population, and export-import coverage ratio. Furthermore, underdeveloped cluster 2 is now somewhat less developed than semi-developed cluster in 2002, which is to be expected since countries which form the cluster in 2007 are removed from the underdeveloped countries cluster, unlike in 2002, when they were separated from the cluster of developed countries. This third cluster has the lowest life expectancy, GDP per capita, export-import coverage ratio, highest age dependency ratio, and female activity rate. The second cluster stands out in the highest long-term unemployment, the lowest elderly employment, and percentage of urban population. The main difference in comparison to 2002 is that now there are two less developed clusters, whereas in 2002 there were two more developed and one underdeveloped cluster. Clustering of Bulgaria with the Baltic countries might be surprising at first, especially considering the fact that 
the GDP per capita of Estonia, Lithuania, and Latvia was EUR 9900, 7700 and 7200 , respectively, while Bulgarian GDP per capita was EUR 3400. However, the reason behind this grouping lies largely with demographic similarities between the countries. Life expectancy and age dependency are two variables which are practically non-distinguishable among the four countries, while the percentage of urban population and female activity rates were also fairly similar between the four countries in comparison with other countries in the sample.

The results of the discriminant analysis for the K-means suggest that variables lifeex, urbpop, and imex are the best discriminators, unlike in 2002. This is probably the reason behind the different cluster separation when compared to 2002 when Ireland, Malta, Cyprus, and the Czech Republic were in the third cluster. The result is in line with economic intuition, as high life expectancy and high share of urban population are characteristics of the most developed economies. Likewise, export-import coverage ratio is a distinctive variable between the core and the periphery since generally there is an agglomeration of economic activity and industrial production in the core (Krugman 1991), and of labour-intensive activities on the periphery (Brülhart 1998). Finally, the classification matrix revealed that all countries are correctly distributed into clusters.

\subsection{EU integration after the crisis}

The analysis of the changes in 2012 is probably the most interesting because it tries to capture the changes caused by the largest economic crisis after the Great Depression in the 1930s. Ward's method with squared Euclidian distances is again conducted on standardised values.

The results for Ward's method are no longer identical to 2002 and 2007. The first cluster is composed of Belgium, France, Austria, Finland, the UK, Denmark, the Netherlands, Germany, and Sweden. The second cluster contains Ireland and Luxembourg and the third cluster is composed of Bulgaria, Estonia, Latvia, Lithuania, the Czech Republic, Hungary, Poland, Slovenia, Slovakia, Cyprus, Malta, Romania, Greece, Croatia, Spain, Portugal, and Italy. For the first time, one cluster is composed of only two countries. There are very modest distances between Bulgaria, Estonia, Lithuania, and Latvia, which is in line with the third cluster obtained with the K-means method in 2007.

Again, the K-means method of the unhierarchical cluster analysis is conducted for three clusters. The first cluster now contains Belgium, the Czech Republic, Ireland, Spain, France, Italy, Cyprus, Luxembourg, Malta, and Austria and it is denoted as a semi-developed cluster; the second Bulgaria, Estonia, Greece, Croatia, Latvia, Lithuania, Hungary, Poland, Portugal, Romania, Slovenia, and 
Slovakia and it is denoted as an underdeveloped cluster; and the third, developed cluster, is made up of Denmark, Germany, the Netherlands, Finland, Sweden, and the UK. This result is much more intuitive because the third cluster is composed of the most developed EU countries, and it is a cluster which was separated in the hierarchical analysis in 2002 and 2007 with the addition of Germany. Based on cluster centre distances (from 0.27 to 0.53 ), it can be concluded that this cluster is fairly homogeneous. It is important to stress that differing labels between clusters serve as orientation in the EU context and are relative. For example, this analysis does not categorise France, Italy, or Austria as semi-developed countries. It rather suggests that from the analysis conducted on this set of variables, these countries fare somewhat worse in comparison with countries from the developed cluster. Furthermore, if a country was classified as developed in 2007 (for example France) and semi-developed in 2012, it does not mean that this country was developing backwards. Instead, this can be interpreted as coping moderately worse than the countries in developed cluster in this five-year period. Obviously, the crisis accentuated some inherent structural problems with some economies. This is probably the reason behind some old MS that were labelled as developed in 2007 and then labelled as semi- or underdeveloped in 2012 (such as Italy, France, Spain, and Belgium). For example, in 2007, few were aware of the real estate price bubble. Bond yields on almost all EU member states were roughly on the same level (Lane 2012). Suddenly, the crisis struck and the weaknesses of some economies became apparent. Once the bubbles burst and bond yields diverged, it became obvious that development achievements from 2007 of some countries were built on rotten foundations.

The disparities between clusters are apparent from the graph of means shown in Figure 3.

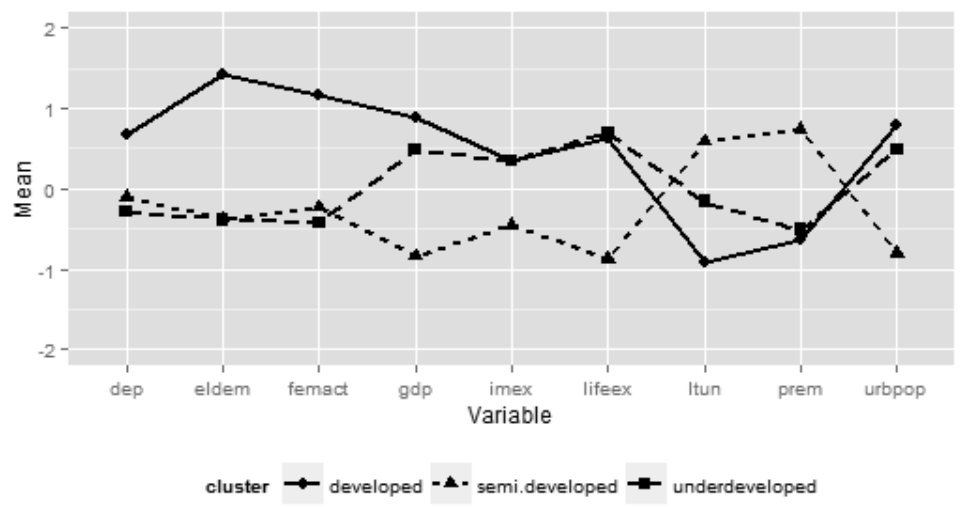

Figure 3. Means of the three clusters in 2012 (K-means) 
The developed cluster has by far the lowest long-term unemployment, the largest elderly employment, and female activity rates as well as the largest GDP per capita and percentage of urban population. The second cluster is by far the least developed; it contains the undeveloped European periphery. Obviously, the crisis struck the periphery more heavily. The K-means results in 2012 suggest discontinuance of observed convergence in the earlier period.

Discrimant analysis is conducted to check the results of K-means method. Variable lifeex remains the best discriminator, but the second best discriminator is variable eldem. It is surprising that GDP per capita was never a particularly strong discriminator. That is probably a result of larger differences in other determinants of development than in the size of the economy per se. The classification matrix shows that all countries are correctly grouped into clusters.

These significant changes that occurred in 2012 require further explanation. Obviously, the crisis played an important role, but neither should the role of macroeconomic management prior to and after the crisis be underestimated. Long before the creation of EMU, there were warnings about the potential impact of asymmetric shocks and the capacity of member countries to withstand them successfully (Wyplosz1997). Obviously, there were significant differences in macroeconomic management between different countries, mainly in fiscal policy measures. These differences are apparent in the country clustering of 2012. For example, when taking into account the loans to private sector from domestic banks and current account balances, it is no longer surprising that Germany and France are not part of the same cluster. As Lane (2012) emphasises, while Greece, Ireland, Portugal, Spain, Italy, and France accumulated the private sector debt in the period 1998-2007, Germany was deleveraging in the same period. Likewise, while France was moving around zero current account balance and other countries accumulated deficits, Germany accumulated a current account surplus of $5.1 \%$ of GDP in the period 2003-2007 (Lane 2012). Interestingly, all countries in the most developed cluster but the United Kingdom have one distinctive characteristic: significant current account surpluses (Schmitz - von Hagen 2011; World Bank 2013), which suggests that trade imbalances indeed play an important role in the development of EU member states. Therefore, with the benefit of hindsight, the conclusion of Schmitz - von Hagen (2011) that "the observed current account balances should be regarded as signs of proper functioning of the euro area rather than sign of improper macro-economic adjustment" could nowadays be regarded as reversed. Furthermore, apart from different policies pursued before the crisis, the sudden halt in mentioned FDI movements from the previous period should also be mentioned. As a result of the crisis, investors' mistrust and scepticism exacerbated the crisis in some countries, which depended heavily on 
FDI inflows, or, more precisely, in countries that had a higher exposure to foreign portfolio investments and foreign loans (Tong - Wei 2011).

\section{DISCUSSION AND CONCLUSION}

This paper analysed the effects of (i) the biggest enlargement of the EU in its history, and (ii) the impact of the crisis on the grouping of countries according to selected variables. The impact of the enlargement was positive: if the slow convergence that Europe experienced in the period from 2002 to 2007 would have continued, then European integration would have had a bright perspective. However, the conducted cluster analysis showed that this was not the case between 2007-2012. Multivariate analysis showed that the countries grouped differently into clusters in different years according to our selected variables. Furthermore, the differences had risen between 2007 and 2012, which suggest that disparities between most developed and less developed MS increased. Moreover, NMS never clustered with the core countries, bar in 2007, when only the Czech Republic, Cyprus and Malta found their way into developed cluster, mainly due to large FDI inflow (Avery et al. 2009) which improved their economic performances. However, further analysis showed that this "clustering with the big players" was only short-term, which suggests that less developed EU member states need to find different mechanisms to kick-start their economies after the crisis as a means to catch up with the European core. Another important point to note is that the most developed countries. i.e. Denmark, Germany, the Netherlands, Finland, Sweden, and the UK, formed the developed cluster in 2012 by themselves, which calls attention to their resistance to the crisis relative to their less developed peers.

Hence, the two pillars of European integration, the European single market mechanism and cohesion policy successfully promoted market conditions for convergence before the crisis. However, they did not safeguard this success from the instability caused by the global financial crisis. While it would be appealing to pinpoint the lack of redistribution or inability of market mechanism to achieve the goal of integration in spite of the EU cohesion supports, it is too difficult to assess the contribution of numerous different factors on the observed divergence to claim that more redistribution would lead to different outcomes. This is also connected to the different policies adopted before and during the crisis. Although the main purpose of our research was to determine the country clusters due to eastern enlargement and the great recession, different approaches followed by different countries still significantly influence the results. Still, the analysis showed which countries used the enlargement to the best of their interest and which countries 
were successful in building the strong foundation that could endure the crisis somewhat painlessly.

Our results are in line with expectations - the core copes well in spite of the crisis, while the periphery (containing principally NMS) finds itself in a difficult economic situation. However, caution is needed when interpreting this conclusion. While the recession and the eastern enlargement certainly played an important role in determining the cluster membership of the countries, it is important to bear in mind that policies adopted by the governments as well as other factors such as the competitiveness of the economy and the efficacy of institutions also influenced cluster membership. Obviously, it should be acknowledged that the core countries overcame the crisis because of their macro-management. Fiscal discipline and responsibility enabled them to stay liquid even when the crisis struck. They had healthy foundations with current account surpluses and high competitiveness, which facilitated their relatively quick recovery after 2009. On the other hand, periphery and some old MS showed worrying levels of fiscal and political irresponsibility. When this is combined with asset price bubbles, it should not be surprising that they fare somewhat worse. Therefore, the real question is how the countries used the opportunities presented from 2002-2007 and how they coped with the challenges in the next period with regard to their EU membership. However, the argument that every individual country is exclusively responsible for itself is not overly convincing since it blurs the role of the EU and cohesion policy. European integration should create a buffer to external shocks at least to some extent; the latest crisis exposed its deficiencies, especially in combination with misplaced policies in some MS. This result raises questions about the ability of European institutions to ensure responsible behaviour and effective policies through multi-level governance. Furthermore, in 10 years, even the countries which showed admirable improvements on most fronts (such as the Czech Republic for example) did not make it to the developed cluster in 2012, which is somewhat worrying.

These results affirm the conclusion of Halmai - Vásáry (2011) which they call the "convergence crisis". Core countries fear that the moral hazard would be too large if they were to help the periphery, i.e. undeveloped countries would not have a genuine incentive to overcome the crisis through their own efforts. Indeed, how would Germany, for example, who was deleveraging and focusing on export growth before the crisis convince its taxpayers they should help their fellow Europeans (in Greece, Spain, Italy, etc.). On the other hand, periphery countries are blaming the core for imposing austerity measures and deepening their difficult economic condition. This again brings out the debate on the fiscal union (Bordo et al. 2013). As Dăianu (2012) emphasises, fiscal rules, surveillance, and peer pressure are not enough for strengthening the cohesion of the EU. Furthermore, Müller 
et al. (2014) argue that the debates on how to deal with the crisis have powerfully revealed that the legitimacy deficit of the EU constitutes a pressing problem for the future of European integration. Because of this political turmoil, it is hard to foresee a significant economic resurrection in the periphery, which is why the success of European integration emphasised by Breuss (2009) and Vachudova (2013) is questionable today. One thing to be optimistic about is the lower age dependency ratio in less developed EU countries in all observed years. Obviously, it represents their strength in comparison with developed countries because their pension systems will be less burdened and they have a younger workforce which fares better with potential technological change. However, in the future, this could also be influenced by different migration policies inside the EU.

Although the conclusion of the politically destabilising effect of the division of Europe into a core and a periphery is consistent with recent literature (Samary 2012; Bellofiore 2013), the presented analysis has some inherent disadvantages:

(1) The selected variables are not a perfect description of development, but mere approximations. Their selection automatically abstracted some other significant moments such as institutions, the efficiency of the political system, democracy, inequality within countries, etc. It is important to be aware of this limitation since the cluster membership of the countries is indeed indirectly influenced by the institutional and political context of the respective country, as mentioned above, and it is worth exploring further.

(2) It is implicitly assumed that differences between countries over the years are affected only by European integration, which is also connected to the issue mentioned above. Actually, this is not a strong assumption since it is likely that European integration indirectly impacted economic performance through reforms and policies adopted during the accession as well as through capital inflows from Western Europe.

(3) The list of variables used is not exhaustive, and other variables could influence the country clustering differently. However, the aim of this paper is to cluster the member states across different years and observe the discrepancies by using the same variables, rather than quantify economic development per se. Therefore, the set of indicators used is considered appropriate for the purpose of this research. In line with this, expanded models in future research would yield more in-depth comprehension about the EU integration and economic development nexus.

Despite these limitations, several stylised facts can be drawn from the analysis: (i) at the beginning of the $21^{\text {st }}$ century, there was some indication of cohesion in EU-28, but it was probably more a result of enthusiasm and general economic upturn in this period than a result of quality and coordination of policies at EU level; (ii) some countries used the opportunities presented in the first period better than 
their peers and even grouped with the most developed EU member states; (iii) point (i) was highlighted when the crisis struck and revealed and emphasised the disparities between the core and the periphery; and (iv) these revealed inequalities in the level of development were the result of the combination of misplaced policies before and after the crisis in some MS and some inherent disadvantages in the EU-level management, mainly related to the lack of political and fiscal union (Fuest - Peichl 2012; Bordo et al. 2013).

As Panagiotou (2013) already noted, the economic situation in which NMS found themselves since the beginning of the crisis could also prove significant for the enthusiasm of EU membership candidates. If there is no robust evidence of cohesion inside the European integration, their incentive to join will be indeterminate. Unfortunately, at this moment in time, such evidence does not exist; quite contrary, we exhibit some slight clue that in the midst of the crisis the EU has wandered off the cohesion path from the beginning of the $21^{\text {st }}$ century.

\section{REFERENCES}

Agnew, J. (2001). How Many Europes? The European Union, Eastward Enlargement and Uneven Development. European Urban and Regional Studies, 8(1): 29-38.

Alfaro, L. - Ozcan-Kalemli, S. - Volosovych, V. (2007): Capital Flows in a Globalized World: The Role of Policies and Institutions. In: Capital Controls and Capital Flows in Emerging Economies: Policies, Practices and Consequences. University of Chicago Press, pp. 19-72.

Arnold, J. M. - Javorcik, B. - Mattoo, A. (2011): Does Services Liberalization Benefit Manufacturing Firms? Evidence from the Czech Republic. Journal of International Economics, 85(1): 136-146.

Avery, G. - Faber, A. - Schmidt, A. (2009): Enlarging the European Union: Effects on the New Member States and the EU. Brussels: Trans European Policy Studies Association.

Baležentis, T. - Baležentis, A. - Brauers, W. K. (2011): Multi-Objective Optimization of Wellbeing in the European Union Member States. Ekonomska istraživanja, 24(4): 1-15.

Bellofiore, R. (2013): Two or Three Things I Know about Her': Europe in the Global Crisis and Heterodox Economics. Cambridge Journal of Economics, 37(3): 497-512.

Bénétrix, A. S. - Lane, P. R. (2013): Fiscal Cyclicality and EMU. Journal of International Money and Finance, 34: 164-176.

Bogumil, P. (2014): Composition of Capital Inflows to Central and Eastern Europe (CEE) - is Poland Different? ECFIN Country Focus, 11(8): 1-9.

Boldrin, M. - Canova, F. (2003): Regional Policies and EU Enlargement. In: Funck, B. - Pizzati, L.: European Integration, Regional Policy, and Growth. Washington: The World Bank.

Bordo, M. D. - Jonung, L. - Markiewicz, A. (2013): A Fiscal Union for the Euro: Some Lessons from History. CESifo Economic Studies, 59(3): 449-488.

Bouvet, F. (2010): EMU and the Dynamics of Regional Per Capita Income Inequality in Europe. The Journal of Economic Inequality, 8(3): 323-344.

Breuss, F. (2009): An Evaluation of the EU' Fifth Enlargement with Special Focus on Bulgaria and Romania. In: Keereman, F. - Szekely, I.: Five Years of an Enlarged EU. Berlin: Springer, pp. 221-248. 
Brülhart, M. (1998): Economic Geography, Industry Location and Trade: The Evidence. The World Economy, 21(6): 775-801.

Dăianu, D. (2012): EURO Zone Crisis and EU Governance: Tackling a Flawed Design and Inadequate Policy Arrangements. Acta Oeconomica, 62(3): 295-319.

Dinan, D. (2005): Ever Closer Union: An Introduction to European Integration. Boulder: Lynne Rienner.

Disney, R. - Hawkes, D. (2003): Why has Employment Recently Risen among Older Workers in Britain? In: Dickens, R. P. G.: The Labour Market under New Labour: The State of Working Britain. New York: Palgrave, pp. 53-70.

Dobre, A. M. (2010): Europeanization and New Patterns of Multi-Level Governance in Romania. Southeast European And Black Sea Studies, 10(1): 59-70.

European Commission (2014): Eurostat. Luxembourg.

Fuest, C., - Peichl, A. (2012): European Fiscal Union: What Is It? Does It Work? And are there Really 'No Alternatives'? IZA Policy Paper, No. 39.

Hagen, T. - Mohl, P. (2009): Econometric Evaluation of EU Cohesion Policy: A Survey. ZEW Discussion Papers, No. 09-052.

Halmai, P., - Vásáry, V. (2011): Crisis and Economic Growth in the EU. Acta Oeconomica, 61(4): 465-485.

Hlavac, M. (2010): Has EU Enlargement been, and will it Continue to be, a Success? An Evaluation of EU Enlargement's Effects on Policies Pursued by Candidate Countries. Munich Personal Repec Archive, No. 28075.

Kahanec, M. - Zaiceva, A. - Zimmermann, K. F. (2010): Lessons from Migration after EU Enlargement. In: Kahanec, M. - Zimmermann, K. F.: EU Labor Markets after Post-Enlargement Migration. Berlin: Springer, pp. 3-45.

Kamps, C. - Leiner-Killinger, N. - Martin, R. (2009): The Cyclical Impact of EU Cohesion Policy in Fast Growing EU Countries. Intereconomics, 44 (1): 23-29.

Krugman, P. (1991): Increasing Returns and Economic Geography. The Journal of Political Economy, 99: 483-499.

Kurnoga-Živadinović, N. - Dumičić, K. - Čeh-Časni, A. (2009): Cluster and Factor Analysis of Structural Economic Indicators for Selected European Countries. WSEAS Transactions on Business and Economics, 6(7): 331-341.

Lane, P. R. (2012): Sovereign Debt Crisis. The Journal of Economic Perspectives, 26(3): 49-67.

Lane, P. R. - McQuade, P. (2014): Domestic Credit Growth and International Capital Flows. The Scandinavian Journal of Economics, 116(1): 218-252.

Lane, P. R. - Milesi-Ferretti, G. M. (2007): Capital flows to Central and Eastern Europe. Emerging Markets Review, 8(2): 106-123.

Leschke, J. - Watt, A. (2010): How do Institutions Affect the Labour Market Adjustment to the Economic Crisis in Different EU Countries? European Trade Union Institute, ETUI: Working Paper, Brussels.

Lipshitz, L. - Lane, T. - Mourmouras, A. (2006): Capital Flows to Transition Economies: Master or Servant? IMF Working Paper, No. 02/11.

López-Tamayo, J. - Ramos, R. - Suriñach, J. (2014): Institutional and Socio-Economic Convergence in the European Union. Croatian Economic Survey, 16(2): 5-28.

Martin, P. (2005): The Geography of Inequalities in Europe. In: Kochendörfer-Lucius, G. Pleskovic, B. (eds): Spatial Disparities and Development Policy Washington: The World Bank, pp. 239-259.

Meardi, G. (2012): Social Failures of EU Enlargement: A Case of Workers Voting with their Feet. New York and London: Routledge. 
Müller, M. - Reckling, T. - Weiß, A. (2014): Introduction - Communicating European Integration - A Historical Perspective. Journal of Contemporary European Research, 10(1): 4-11.

Nickell, S. (1997): Unemployment and Labor Market Rigidities: Europe versus North America. The Journal of Economic Perspectives, 11(3): 55-74.

O’Sullivan, A. (2011): Urban Economics. New York: McGraw-Hill.

Ottaviano, G. - Taglioni, D. - di Mauro, F. (2007): Deeper, Wider and More Competitive? Monetary Integration, Eastern Enlargement and Competitiveness in the European Union. ECB Working Paper series, December, No. 847.

Panagiotou, R. (2013): The Greek Crisis as a Crisis of EU Enlargement: How will the Western Balkans be Affected? Southeast European and Black Sea Studies, 13(1): 89-104.

Reinert, E. S. - Kattel, R. (2007): European Eastern Enlargement as Europe's Attempted Economic Suicide? The Other Canon Foundation (Norway) and Tallinn University of Technology (Estonia) Working Papers in Technology Governance and Economic Dynamics, No. 14.

Sala-i-Martin, X. (1996): Regional Cohesion: Evidence and Theories of Regional Growth and Convergence. European Economic Review, 40(6): 1325-1352.

Samary, C. (2012): Eastern Europe Faced with the Crisis of the System. In: Leplat, F. - Onaran, Ö. (eds): Capitalism. Crises and Alternatives. London: Resistance Books, pp. 189-219.

Schmitz, B. - von Hagen, J. (2011): Current Account Imbalances and Financial Integration in the Euro Area. Journal of International Money and Finance, 30(8): 1676-1695.

Tong, H. - Wei, S. J. (2011): The Composition Matters: Capital Inflows and Liquidity Crunch During a Global Economic Crisis. The Review of Financial Studies, 24(6): 2023-2052.

Vachudova, M. A. (2013): EU Leverage and National Interests in the Balkans: The Puzzles of Enlargement Ten Years on. Journal of Common Market Studies, 52(1): 1-17.

Weinhold, D. - Nair-Reichert, U. (2001): Causality Test for Cross-Country Panels: A New Look at FDI and Economic Growth in Developing Countries. Oxford Bulletin of Economics and Statistics, 63(2): 153-170.

Welcome Europe (2015): European Glossary of European Commission: http://www.welcomeurope. com/european-funding-glossary/definition/economic-social-cohesion+545. Retrieved February 17, 2015, from

Winiecki, J. (2012): Pressing Problems of The Euro Zone - and Beyond (or: What May Break the Camel's Back). Acta Oeconomica, 62(4): 423-434.

World Bank. (2013): World Databank. World Development Indicators. World Bank.

Wyplosz, C. (1997): EMU: Why and How It Might Happen. The Journal of Economic Perspectives, 11(4): 3-21. 


\section{APPENDIX: CLUSTER ANALYSIS SUMMARY}

2002

Developed cluster

\begin{tabular}{|l|}
\hline Denmark \\
Germany \\
Netherlands \\
Finland \\
Sweden \\
UK \\
Belgium \\
Spain \\
France \\
Italy \\
Luxembourg \\
Austria \\
\hline
\end{tabular}

Underdeveloped cluster

\begin{tabular}{|l|}
\hline Bulgaria \\
Estonia \\
Latvia \\
Lithuania \\
\hline Greece \\
Croatia \\
Hungary \\
Poland \\
Portugal \\
Romania \\
Slovenia \\
Slovakia \\
\hline Semi-developed \\
cluster \\
\hline \begin{tabular}{l} 
Czech Republic \\
Ireland \\
Cyprus \\
Malta \\
\hline
\end{tabular} \\
\hline
\end{tabular}

2007

2012

Developed cluster

\begin{tabular}{|l|l|}
\hline Denmark & \multicolumn{1}{|l|}{ Germany } \\
Netherlands & Denmark \\
Finland & Germany \\
Sweden & Netherlands \\
UK & Finland \\
Sweden \\
\hline
\end{tabular}

Belgium

Spain

France

Italy

Luxembourg

Austria

Czech Republic

Ireland

1 Cyprus

Malta

Underdeveloped

cluster 1

Greece
Croatia

Semi-developed

cluster

Belgium

Spain

France

Italy

Luxembourg

Austria

Czech Republic

Ireland

Cyprus

Malta 